\title{
The relationship between medical law and good medical ethics
}

\author{
Emily Jackson
}

\section{Correspondence to Professor Emily Jackson, Department of Law, LSE, WC2A 2AE, London, UK; e.jackson@lse.ac.uk}

Received 20 August 2014 Revised 7 October 2014

Accepted 8 October 2014
CrossMark

To cite: Jackson E. J Med Ethics 2015;41:95-98.

\begin{abstract}
In the UK, medical ethics and law are often thought of and taught together, but while 'good medical ethics' is often reflected in law-the need to obtain a patient's adequately informed consent, for example-this is not necessarily the case. Sometimes medical ethics is more demanding than law; at other times, perhaps counterintuitively, the law appears to ask more of doctors than does good medical ethics.
\end{abstract}

Doctors may have difficult questions to resolve when their legal duties appear to conflict with their perception of their ethical responsibilities. The law might seem to require a doctor to behave in a way which conflicts with his or her personal morality or beliefs. It is also possible that parliament could pass a statute with which the doctor must comply, but where compliance appears to conflict with her primary responsibility to make the care of her patient her first concern.

In short, there are a series of tensions and discrepancies between what is 'legal' and what is 'ethical' in the context of medical treatment, which may be confusing for healthcare professionals and patients alike. This is exacerbated by the tendency to lump medical law and medical ethics together: there are courses, textbooks, research centres and aspects of medical training called 'medical ethics and law' or 'medical law and ethics'. Of course, there is considerable overlap in the subject matter of a medical ethics textbook and a medical law text. But teasing out some of the differences between what is demanded by medical ethics and what is required by law suggests that the relationship between ethics and law is perhaps more slippery than is sometimes assumed.

In this short commentary, I will contrast guidance to doctors in the UK on what is ethical with English law, relying on the ethical guidance which is provided to doctors by professional bodies, ${ }^{1}{ }^{2}$ rather than starting from first principles. I do so not because I wish to claim that this sort of guidance has a monopoly on what is ethical. Rather, the point of this note is to highlight some of the confusing signals that are sent to doctors about both the equivalence and the divergence of legal and ethical requirements, and this is best illustrated by contrasting the law as laid down in a statute or embodied in the common law, and ethics, as set out in these sorts of codes of conduct or good practice.

\section{IS MEDICAL ETHICS MORE DEMANDING OF DOCTORS THAN LAW?}

There are times when guidance on how to behave ethically demands more of doctors than compliance with the law. The imbalance of power in the doctor-patient relationship means that doctors must not abuse the trust that is placed in them. It would not be unlawful for a doctor to have a sexual relationship with a consenting, adult patient, but it would be unethical.

Where the same medical encounter is governed both by the common law and by professional standards and ethical guidance, the profession not infrequently requires more of itself than is required in order to avoid legal challenge. A good example of this is the requirement to provide the patient with sufficient information before she consents to medical treatment. A patient who is inadequately informed about the treatment they are about to receive might have a remedy in tort law if the failure to provide them with that information: (A) could be said to be negligent and (B) caused them physical harm. In determining whether an inadequate disclosure was negligent, the courts were historically guided by what the reasonable doctor would do. Although tort law has been moving towards a 'reasonable patient' test for disclosure, where the doctor is under a duty to provide whatever information a reasonable person in the patient's position would normally want to know, this is also an objective test which delivers standardised information to all patients, rather than tailoring it to the perhaps idiosyncratic preferences of the individual.

By contrast, General Medical Council (GMC) guidance explicitly adopts a subjective, patientspecific standard of care.

\section{The amount of information about risk that you should share with patients will depend on the indi- vidual patient and what they want or need to know.... \\ 31. You should do your best to understand the patient's views and preferences about any proposed investigation or treatment, and the adverse out- comes they are most concerned about. You must not make assumptions about a patient's under- standing of risk or the importance they attach to different outcomes. ${ }^{3}$}

If ethical guidance to doctors could always be relied upon to be more demanding and more detailed than a doctor's legal duties, the relationship between medical law and medical ethics might look quite straightforward. Confusingly, however, there are times when this weighting is reversed, and the law contains a set of much more rigorous and detailed requirements. An example would be the Mental Capacity Act $2005 .^{4}$ 
The GMC's guidance to doctors on making treatment decisions when a patient lacks capacity borrows extensively from the Mental Capacity Act, with its focus both on how to maximise the number of patients able to make decisions for themselves, and on ensuring that decisions taken on behalf of a person who lacks capacity as far as possible reflect their beliefs, values and preferences. ${ }^{3}$ The GMC guidance on the additional support a patient may need in order to make a decision for themselves is contained in one paragraph (para 21). ${ }^{3}$ By contrast, the Mental Capacity Act, with its accompanying Code of Practice, is much more detailed. The Act contains a principle of assisted decision making: 'A person is not to be treated as unable to make a decision unless all practicable steps to help him to do so have been taken without success' (section 1(1)3), which is bolstered by a statutory requirement to give information in a way that the patient is likely to be able to understand:

A person is not to be regarded as unable to understand the information relevant to a decision if he is able to understand an explanation of it given to him in a way that is appropriate to his circumstances (using simple language, visual aids or any other means) (section 3(2)).

The Code of Practice goes even further. It has a whole chapter entitled 'How should people be helped to make their own decisions? $?^{3}$ This goes into extraordinary detail about how doctors should help people to be able to make decisions for themselves, including, for example, exhortations to:

- Speak at the right volume and speed, with appropriate words and sentence structure. It may be helpful to pause to check understanding or show that a choice is available.

- Break down difficult information into smaller points that are easy to understand. Allow the person time to consider and understand each point before continuing (para 3.10). ${ }^{4}$

Although there is not a substantive difference between the law and GMC guidance-both stress the need to help patients to make decisions for themselves-in complete contrast to the rules on consent, the law here is, in fact, much more specific on what doctors actually need to do.

\section{WHEN ETHICS AND LAW CONFLICT WITH EACH OTHER}

There are two ways in which a doctor might find herself concerned about a conflict between her duty to comply with the law and her ethical responsibilities. The first is where her legal obligations appear to conflict with her personal beliefs about the ethical acceptability of a particular course of action.

In some circumstances, healthcare professionals are given a specific right of conscientious objection in order that they can excuse themselves from providing treatment which they believe to be unethical. These rights have tended to be both exceptional and quite narrowly drawn. In relation to abortion, for example, until the decision of the Scottish Court of Session (Inner House) in Doogan $v$ Greater Glasgow and Clyde Health Board, ${ }^{5}$ at the time of writing under appeal to the Supreme Court, it appeared that the right of conscientious objection was confined to actually participating in the termination of a pregnancy. Although it remains to be seen what the Supreme Court will decide, in Doogan, midwives who worked as 'labour ward coordinators' were held to have a right to conscientiously object to duties described as 'delegating, supervising and/or supporting other staff in the participation and provision of care to patients undergoing medical termination.'

It is not clear where this leaves a doctor who does not want to have to refer a woman for a termination. Before Doogan, it was assumed that the right to conscientiously object did not extend to a right to refuse to refer a woman for a termination of pregnancy, regardless of the doctor's personal difficulty in doing so.

Although not subject to a statutory right of conscientious objection, some doctors have concerns about withdrawing lifeprolonging treatment. In Re B (Adult: Refusal of Treatment), ${ }^{6}$ Ms B, a competent, adult woman, wished to be withdrawn from the ventilator which was keeping her alive. Once the judge, Dame Elizabeth Butler-Sloss P, had determined that Ms B was competent, it followed that her decision to refuse treatment had to be respected. Indeed, to continue to treat Ms B in the face of a competent refusal amounted to an assault. Despite this, Dame Elizabeth Butler-Sloss P was sympathetic towards the doctors involved in her care, who 'could not bring themselves to contemplate that they should be part of bringing Ms B's life to an end by the dramatic ... step of turning off the ventilator'. Dr C, for example, 'did not feel able to agree with simply switching off Ms B's ventilation. She would not be able to do it. She felt she was being asked to kill Ms B.'

Regardless of the finding that in continuing to treat Ms B, the doctors were acting unlawfully and indeed were, in legal terms, assaulting her, their reluctance to participate in bringing about her death was respected and Ms B was moved to another hospital where the ventilator was removed.

At first sight, it seems extraordinary that a doctor should be permitted to conscientiously object to refraining from assaulting his patient. On the other hand, it could be argued that the real oddity here is the law's pragmatic classification of the deliberate withdrawal of life support as an 'omission'. Although most of us would regard physically withdrawing a patient from a ventilator as an 'action', the law treats it as an omission in order to avoid its otherwise inevitable categorisation as murder. Dame Elizabeth Butler-Sloss $\mathrm{P}$ was simply acknowledging that bringing about a patient's death can be difficult, regardless of the fact that it is achieved by what the law treats as 'a failure to act'.

In any event, it is clear that if alternative arrangements could not have been made for Ms B, the doctors' reluctance to participate in Ms B's death could not have been respected and they would have had to comply with her wishes, regardless of any discomfort and distress that this would have caused them. The doctor's overarching duty is to make the care of the patient her first concern. If a patient is seeking a treatment that is lawful, but with which the doctor disagrees on moral grounds, the doctor's primary duty continues to be to the patient. The doctor must not abandon her patients whenever she disapproves of their choices and must ensure their continuity of care. If it is possible for the doctor to hand the care of a patient over to another doctor, it may be acceptable for the doctor to withdraw from that person's care. ${ }^{7}$ If this is not possible, the doctor must be able to find it within herself to carry on caring for the patient. A doctor who is unable always to make the care of her patients her first concern simply cannot fulfil the most basic duty of a doctor. ${ }^{8}$

More difficult still is the second way in which a doctor's ethical responsibility might conflict with her legal duties, namely, when a doctor believes that the law is requiring her to do something that is at odds with her over-riding ethical duty to make the care of her patient her first concern. This is most likely to happen when legislation attempts to restrict a doctor's discretion to act in his patient's best interests. Whenever doctors are placed under mandatory reporting duties, for example, their freedom to judge that, in a particular case, reporting would do more harm than good is removed. If doctors are instructed that they must not treat someone who is not ordinarily resident in 
the UK unless that person has the resources to pay for treatment, once again, the doctor's freedom to do what she thinks is best for that patient is restricted.

Mandatory reporting is popular with tabloid journalists who want to appear to be taking a tough and uncompromising approach to illegal and/or abusive behaviour. If we are concerned about the widespread failure to prosecute those who are engaged in female genital mutilation, slavery, human trafficking or the sexual abuse of children, for example, then it is easy to see why some might argue that doctors and other relevant professionals should be under a duty to report their suspicions to the police.

The problem with mandatory reporting is not that it seeks to encourage reporting or make it routine, but rather that it removes the possibility that, in a rare case, a healthcare professional may judge that disclosure to the police, or another body, may place the victim in immediate and grave danger. Additionally, if such victims know that reporting is mandatory, perhaps because they have previously experienced its consequences, they may be less likely to come forward to seek medical attention regardless of the seriousness of their injuries. In two ways, then, mandatory reporting could jeopardise the health or even the life of the victim of serious crime.

On the reporting of crime and abuse, professional ethical guidance starts from the presumption that prompt reporting is essential in order to protect the victim. There is no doubt from reading the GMC's guidance on Protecting Children and Young People that doctors are under a duty to report suspicions of abuse or neglect to an appropriate agency. ${ }^{9}$ However, the guidance also acknowledges that there may be rare cases where immediate reporting would conflict with the duty to make the care of the patient one's first concern (para 39). ${ }^{9}$ By contrast, mandatory reporting duties would seek to remove the doctor's judgement from the equation.

The current UK government's stance on mandatory reporting is confusing. It appeared to recognise its disadvantages in its response to the Home Affairs Select Committee's report on child sexual exploitation:

\footnotetext{
The international evidence on the effectiveness of mandatory reporting systems keeping children safer is far from conclusive. Much of the evidence suggests that mandatory reporting systems cause a steep rise in the number of reports made, a large percentage of which are not substantiated. Consequently, child protection services are likely to be overloaded with work in investigating unsubstantiated reports, with an adverse impact on the resources available to help children and families in need. A mandatory reporting system could also potentially act as a barrier to children disclosing issues or seeking help, especially perhaps in a sexual health context. ${ }^{10}$
}

A year later, the prime minister appeared to be more enthusiastic about mandatory reporting in the case of FGM. According to his twitter account, David Cameron stated: 'I'll make reporting FGM mandatory for doctors, teachers and social workers. Let's end this abhorrent practice once and for all.'

And despite its recognition of the risks of mandatory reporting, section 44(1) of the government's Modern Slavery Act 2014 contains a mandatory reporting duty: 'A specified public authority must notify the National Crime Agency [NCA] if it has reason to believe that a person may be a victim of slavery or human trafficking.' Section 44 (3) does specify that an adult victim's name should not be disclosed without their consent, but contains no such provision for trafficked children. Of course, reporting to the NCA should be routine in such cases, but if the doctor judges that immediate reporting might put a child victim in grave danger, he or she has no discretion to delay reporting.

A different set of circumstances when the law might appear to demand that a doctor acts contrary to her first responsibility to her patient is when doctors are required to participate in efforts to restrict access to National Health Service (NHS) services to those who are entitled to them. To be eligible for free NHS care, a person has to be 'ordinarily resident' in the UK, thus excluding illegal immigrants and failed asylum seekers. Clinicians are entitled to treat people regardless of their immigration status if treatment is urgently required. But if treatment could wait until the person leaves the UK, treatment should not be provided, regardless of how beneficial it would be for the patient. Clinicians should also inform their trusts' Overseas Visitors Manager if they become aware that a patient is not ordinary resident in the UK, thus potentially jeopardising their ability to treat that patient in her best interests. Of course, it could be argued that doctors have a role to play in ensuring the sustainability of the NHS, which could not afford to provide limitless treatment to patients from across the world. Nevertheless, some doctors may find it difficult to assume the role of the enforcer of immigration rules, rather than always simply acting in the best interests of the patient in front of them.

\section{CONCLUSION}

Although there may be tensions and discrepancies as well as similarities between a doctor's legal duties and her ethical responsibilities, her duty is to comply with both the law and with professional ethical guidance. Even where a doctor finds compliance with the law difficult, perhaps because it appears to her to be at odds with her ethical beliefs, compliance is not optional. It could be argued that doctors indirectly also have a legal duty to comply with GMC good practice guidance, because a doctor's registration can be put at risk by a failure to do so.

One of the principal difficulties for doctors lies in working out what their legal responsibilities are, since, unlike GMC guidance, they are not set out in a set of easily searchable documents on an accessible website. Where ethical guidance demands more of doctors than the law, as is the case with the duty to provide sufficient information to the patient before she gives consent, the inaccessibility of legal sources may not matter very much. If the doctor complies with GMC guidance on information provision, she will undoubtedly also have acted non-negligently. Where, in contrast, the law sets out more rigorous and demanding requirements than ethical guidance, it is not always clear that this will be obvious or the details easily accessible to the medical profession.

Post-legislative scrutiny of the Mental Capacity Act 2005 provides a vivid illustration of the fact that passing legislation is not necessarily sufficient to change behaviour. The Mental Capacity Act 2005 is widely acknowledged to be a strikingly patientfocused statute, which the postlegislative scrutiny Select Committee found was described in 'unusually enthusiastic language' by stakeholders. It was not well understood, however, and had not been properly implemented:

The empowering ethos of the Act has not been widely implemented. Our evidence suggests that capacity is not always assumed when it should be. Capacity assessments are not often carried out; when they are, the quality is often poor. Supported decisionmaking, and the adjustments required to enable it, are not well embedded. The concept of unwise decision-making faces institutional obstruction due to prevailing cultures of risk-aversion and 
paternalism. Best interests decision-making is often not undertaken in the way set out in the Act: the wishes, thoughts and feelings of $\mathrm{P}$ are not routinely prioritised. ${ }^{11}$

In addition to a general lack of awareness of the Act's provisions, crucially, nobody had been given ownership of it and responsibility for its implementation. As a result, clinical practice had remained largely unaffected by what could be described as a dramatic sea change in the law. GMC guidance has 'bite' because a failure to follow it could put a doctor's registration at risk. Not doing everything possible to assist a vulnerable patient to make a decision for herself is a failure to follow the Mental Capacity Act, but without proper oversight, such failures may have been inadvertent and have gone largely unnoticed. In short, while doctors have a duty to act lawfully, as well as ethically, without making the law more accessible and putting in robust mechanisms for accountability, important legislative change may not make the difference that it should.

Competing interests None.

Provenance and peer review Commissioned; internally peer reviewed.

\section{REFERENCES}

1 Key guidance on ethics - an A to Z. London: British Medical Association. http:// bma.org.uk/practical-support-at-work/ethics/ethics-a-to-z

2 Good medical practice: Explanatory guidance. London: General Medical Council. http://www.gmc-uk.org/guidance/ethical_guidance.asp

3 Consent guidance: patients and doctors making decisions together. London: General Medical Council, 2008. http://www.gmc-uk.org/guidance/ethical_guidance/ consent_guidance_index.asp

4 Mental Capacity Act 2005:Code of Practice. London: The Stationery Office Limited, 2007.

5 [2013] CSIH 36.

6 [2002] EWHC 429 (Fam).

7 British Medical Association. Withholding and Withdrawing Life-prolonging Medical Treatment, 3rd edition. London: Blackwell Publishing, 2007.

8 Good medical practice (2013). London: General Medical Council, 2013. http://www.gmc-uk.org/guidance/good_medical_practice.asp

9 Protecting children and young people: the responsibilities of all doctors. London: General Medical Council, 2012. http://www.gmc-uk.org/guidance/ ethical_guidance/13257.asp

10 Child sexual exploitation and the response to localised grooming: Second Report of Session 2013-14 (HC 68-I). London: The Stationery Office Limited, 2013.

11 Select Committee on the Mental Capacity Act 2005 - Report. Mental Capacity Act 2005: post-legislative scrutiny. London: The Stationery Office Limited, 2014. http:// www. publications. parliament.uk/pa/ld201314/ldselect/ldmentalcap/139/13902.htm 